\title{
Improved Mobilization of Hydrocarbons during MEOR Application
}

\author{
Nmegbu, Chukwuma Godwin $\mathrm{J}^{1}$ and Pepple, Daniel Dasigha ${ }^{2}$ \\ ${ }^{1}$ Department of Petroleum Engineering, Rivers State University of Science and Technology, Nigeria. \\ ${ }^{2}$ (Department of Petroleum Engineering, Rivers State University of Science and Technology, Nigeria.
}

\begin{abstract}
Microbial enhanced oil recovery application (MEOR) is a potentially attractive way to recover additional oil from a reservoir. This study reveals the ability of microorganisms for mobilization and displacement of residual oil in sand pack cores by the action of produced biosurfactant. Isolates of hydrocarbonutilizing bacteria were identified as pseudomonas, Bascillus, Citrobacter and Escherichia, using microscopic examination and biochemical tests. Three of the listed microbes were confirmed to be potential biosurfactantproducing microbes by testing the spent culture filtrate of the isolates. Pseudomonas and Escherichia were observed to produce biosurfactants only on nutrient broth, which was observed to emulsify hydrocarbons. The flooding experiment also showed that primary recovery accounts for about $25 \%$ and that of secondary oil recovery (brine chase) approximates $20 \%$ of original oil in place. The maximum oil recovery achieved by tertiary oil recovery (MEOR) using biosurfactants was approximately 50\% OOIP. These biochemical tests conclusively reveal that biosurfactant slugs are technically feasible for maximizing oil recovery by reducing interfacial tension for improved mobilization of hydrocarbons.
\end{abstract}

Keywords: - Biosurfactants, Emulsification, Incubation time, isolates, Microbes.

\section{INTRODUCTION}

In the past, numerous microbial EOR projects have been conducted in various parts of the world with varying degree of certainties. Petroleum microbiology has confirmed has caused the petroleum industry to still consider MEOR as an experimental secondary enhance oil recovery method [1]. Reservoir microbiology has shown that microorganisms are ubiquitous and exists in reservoirs as aerobic, facultative or anaerobic. For MEOR, microbes are isolated, screened and selected before being injected into the reservoir with or without the presence of substrates to support growth and metabolite production. Temperature, salinity, pressure and reservoir permeability are some of the primary factors influencing microbial performance in-situ [2]. The nutritional conditions required for growth of microbes include availability of utilizable source of energy, carbon sources in addition to adequate levels of nitrogen, phosphate and oxygen if are utilizable if microbes are aerobes. Anaerobes on the other hand utilize the hydrocarbon as nutrient sources [3]. Jack et al studied the effects of plugging sandstone cores and the observation that the slime forming bacteria have large effects on permeability reduction than similar non-slime forming species [4]. The effects of rock permeability on microbial transport was examined by Jang et al, who also demonstrated experimentally how biopolymers help modify formation permeability by reducing its sizes and helps in fluid diversion [5]. A demonstration of oil recovery efficiency was conducted using several strains of Berea sandstone cores that was treated with microorganisms was found to recover an average of 30\% more residual light crude oil when compared to water flooding [6].

\subsection{Microbial source}

\section{MATERIALS AND METHODS}

Biosurfactant-producing microbes were isolated from soil samples from a hydrocarbon contaminated site with an electric generating plant to ensure proper identification of the microbes. These Soil samples were recovered from a depth of $0-2$ inches, placed in sterile bottles of $150 \mathrm{ml}$ capacity and transported to the laboratory.

\subsection{Isolation of biosurfactant producing bacteria (BFB)}

The mineral salt model of Okpkowasili [7] was used to isolate the surfactant producing bacteria using vapor phase transportation method. The components of the medium was weighed and dissolved in 1.0litre of deionized water placed in 1.5 litre capacity Erlenmeyer flask. The medium was sterilized by autoclaving at $120^{\circ} \mathrm{C}$ at $15 \mathrm{psi}$ for $15 \mathrm{mins}$, dispersed into sterile Petri dishes and allowed to set (cool). A gram of soil sample was mixed with $9.0 \mathrm{ml}$ sterile saline and diluted serially to a final dilution of $10^{-5}$. The incubation period was to allow the development of an increased microbial population. Discrete colonies that developed on the plates were 
further sub cultured on the sterile nutrient agar slant surfaces in McCartney bottles by streaking technique, incubated at $30^{\circ} \mathrm{C}$ for $24 \mathrm{hrs}$ and preserved culture fur further analysis.

\subsection{Identification of isolates}

The microscopic examination of cell morphology, biochemical tests, substrate utilization of carbon sources, enzyme production and mobility test were employed to characterize and identify the isolates.

\subsection{Microscopic examination of cell morphology}

A smear of the culture was prepared on a clean grease-free glass slide, air-dried and heat fixed. The smear was flooded with crystal violet solution for 30seconds and rinsed in a slow running tap water for 5 seconds. Alcohol (ethanol) was used to decolorize the slide content. The smear was rinsed immediately with water, counter stained with safranin solution for 30seconds and air-dried. The stained smears were then observed under the light microscope using the oil immersion objective lens. Gram B reagent and their composition are presented below.

Gram's stains

- Crystal violet solution

$\begin{array}{ll}\text { Ingredients } & \text { composition } \\ \text { Crystal violet dye } & 0.5 \mathrm{~g} \\ \text { Deionized water } & 100 \mathrm{ml}\end{array}$

- Decolorizer (Alcohol solution)

Ingredients composition $(\% \mathrm{w} / \mathrm{v})$

Ethanol 95.0

- Gram's iodine solution

Ingredient composition

Iodine $\quad 1.0 \mathrm{~g}$

Potassium iodine $\quad 2.0 \mathrm{~g}$

Deionized water $\quad 300 \mathrm{ml}$

- Safranin solution

Ingredients composition

Safranon dye (0) $\quad 2.0 \mathrm{~g}$

Deionized water $\quad 100 \mathrm{ml}$

\subsection{Chemical Analyses of Biosurfactant Extracts.}

Anchrone and phosphate test were used to characterize or classify the biosurfactant (or crude liquid).

\subsubsection{Anthrone test}

The method was adopted from Garhart et al [12]. Ten milliliter of distilled water was added to $0.1 \mathrm{~g}$ extract 1 in a beaker and vigorously shaken. $40 \mathrm{ml}$ of cold Anthrone reagent was added to $10 \mathrm{ml}$ of the sample solution in a beaker and mixed by stirring, incubated in boiling water bath for 10 minutes. Color formation was determined by measuring the absorbance at a wavelength of $25 \mathrm{~nm}$ using colorimeter

\subsubsection{Phosphate analysis}

The ascorbic acid method was adopted in this test. $10 \mathrm{ml}$ of distilled water were added to $0.70 \mathrm{~g}$ of the combined reagent shaken vigorously. $16 \mathrm{ml}$ of the combined reagent were added to the content of the beaker and mixed by swirling, after 15 minutes.

\subsection{Core analysis}

\subsubsection{Sieve Analyses}

The laboratory test sieve was used for the sieve grain size analysis. The sieve consisted of mesh grade arrangement in decreasing order: $2.36 \mathrm{~mm}, 1.18 \mathrm{~mm}, 600 \mu \mathrm{m}, 426 \mu \mathrm{m}, 212 \mu \mathrm{m}$ and $75 \mu \mathrm{m}$. The sand sample was placed in highest mesh grade i.e. $2.36 \mathrm{~mm}$ and the sieve fixed. The power source was turned on and the sieve was shaken for 15 minutes. This was repeated several times until sufficient amount of sample of the required grain size was collected.

\subsubsection{Pore volume and porosity determination}

Ukpe's saturation method was employed [10]. The bulk volume of sand sample required to fill the core holder was determined with graduated cylinder. The sample was weighed dry (wd), saturated and reweighed with water (Ws) (in a beaker). The experimental setup was constructed with glass, consisting of a core holder, chemical reservoirs, pressurized tank and foot pump. The core holder is $2.2 \mathrm{~cm}$ in diameter (internal) and $9.5 \mathrm{~cm}$ 
in length (effective height). The three chemical reservoirs for brine, biosurfactant slug and crude oil were of $250 \mathrm{~m} 1$ capacity each. The pressurized tank and foot pump served as the pressure source to force fluids up the core holder containing the sand sample.

\subsubsection{Core flooding biosurfactant oil displacement:}

The sand sample (unconsolidated) in the core holder was saturated with brine $(10 \% \mathrm{v} / \mathrm{w} \mathrm{NaCl})$, about 1.0 pore volume $(\mathrm{Vp})$. The brine saturated sand core was then flooded with the crude oil until approximately zero water cut in effluent point was obtained. The volume of oil flooded and the irreducible water saturation was determined.Brine flooding commenced after washing the system (manifold) with hot detergent solution and proper rinsing. The flooding continued until residual oil saturation, initial, (Sor) was reached and determined (secondary EOR).

The core was then saturated with about 1.5 pore volume of biosiurfactant solution (spent cultured filtrate) and followed by "chase" brine flooding immediately, until no more oil was produced. This served as zero (0) hour biosurfactant incubation time flooding. The experiment was repeated for different time 24, 48, 72, 96 and 120 hours. The final residual oil saturation (Sore) after biosurfactant saturation (incubation) and subsequently "chase" brine for $0,24,48,72,92$ and 120 hours, and percentage oil recovering was determined.

\subsection{Results for Isolates Characterization and Identification}

\section{EXPERIMENTAL RESULTS}

Morphological and biochemical characteristics of the isolates were observed, six of the eight isolates were Gram negative rods while the remaining two were Gram positive rods. Biochemical tests revealed that two Gram positive rods were bacillus species, four out of the six were Gram negative rods, identified as pseudomonas species, while the other two were identified as citrobacteria and Escherichia.

\subsection{Growth of Isolates on Nutrient Broth and Hydrocarbons Products}

The ability of four isolates GIB2, GIB3, GIB6, AND GIB8 to grow on petroleum products (hydrocarbon) and nutrient broth are as follows; All the four isolates showed heavy growth in the nutrient broth and diesel mineral salts broth. Isolates GIB2 and GIB8 were observed to grow in the kerosene-mineral salt broth, GIB6 showed a weak growth. However, isolate GIB3 did not show growth in the kerosene-mineral salt broth.

\subsection{Results for Chemical Analysis of Biosurfactant extracts.}

The Anthrone Reagent was prepared using 200mg of Anthrone, $100 \mathrm{ml}$ of $\mathrm{H}_{2} \mathrm{SO}_{4}$ (concentrated) and $5.0 \mathrm{ml}$ of Deionized water. For the Anthrone test, the development of deep green color was observed, indicating a positive reaction while retention of light green color will indicate negative reaction.

On the other hand, the absorbance of the solution was measured at a wavelength of $620 \mathrm{~nm}$ using distilled water during the phosphate test. The development of blue color following addition of light green combined reagent indicated a positive test.

The weight of biosurfactant extracts is presented as thus:

Table-1: Weights of biosurfactant from three determinants

\begin{tabular}{|l|l|l|l|l|}
\hline Sample & 1 & 2 & 3 & \\
\hline $\begin{array}{l}\text { Weight of } \\
\text { filtrates } \\
(\mathrm{g} / 40 \mathrm{ml})\end{array}$ & 0.10 & 0.08 & 0.09 & \\
\hline $\begin{array}{l}\text { Weight of } \\
\text { filtrates } \\
(\mathrm{g} / \mathrm{ml})\end{array}$ & $2.5 \times 10^{3}$ & $1.85 \times 10^{3}$ & $2.35 \times 10^{3}$ & \\
\hline $\begin{array}{l}\text { Weight of } \\
\text { filtrates } \\
(\mathrm{mg} / \mathrm{ml})\end{array}$ & 2.50 & 1.86 & 2.5 & \\
\hline
\end{tabular}

The biosurfactant extracts indicated positive tests for anthrone and phosphate tests. These reveal the presences of carbohydrate (glucose) molecule and phosphate indicating, a mixture of glycolipid and phospholipids. Table 2 shows the result of the chemical analysis of the biosurfactant extracts. 
Table-2: Chemical analysis of biosurfactant (crude liquid) extracts

\begin{tabular}{|l|l|l|}
\hline $\begin{array}{l}\text { Chemical } \\
\text { analysis }\end{array}$ & Extract sample & class of biosurfactants \\
\hline Anchrone & + & Glycolipid \\
\hline Phosphate & + & Phospholipid \\
\hline
\end{tabular}

\subsection{Results for Core analysis}

The results of sieve/grain size pore volume and porosity determination are presented below in table 3 .

Table-3: Physical characterization of the sand sample

\begin{tabular}{|l|l|}
\hline Parameter analyzed & Value obtained \\
\hline Grain size & $300 \mu \mathrm{m}<\mathrm{XGS}^{*}$ \\
\hline Pore volume & $12.17 \pm 0.20 \mathrm{~cm}^{3}$ \\
\hline Porosity & $0.309 \pm 0.000$ \\
\hline Irreducible water saturation $\left(\mathrm{S}_{\mathrm{wi}}\right)$ & $0.097 \pm 0.008$ \\
\hline Residual oil saturation $\left(\mathrm{S}_{\mathrm{or}}\right)$ & $0.2735 \pm 0.001$ \\
\hline
\end{tabular}

$\mathrm{xgs}=$ grains size of sand

It indicates that the grains size of the sand sample employed was $300 \mu \mathrm{m}<\mathrm{xgs}<, 426 \mu \mathrm{m}$. The pore volume and porosity of the sand sample were $12.17, \mathrm{I} 0.29 \mathrm{~cm}^{3}$ and $0.309 \pm 0.008$, respectively. The irreducible water saturation $\left(\mathrm{S}_{\mathrm{wi}}\right)$ following oil flooding and residual oil saturation $\left(\mathrm{S}_{\mathrm{or}}\right)$ after brine (water) flooding are also shown in Table 5 . An oil yield of $50.18 \%$ of the residual oil was obtained following tertiary recovery at zero $(0)$ hours of biosurfactant incubation time (BIT). Sharp increase of oil recovery was obtained from $50.18 \%$ at zero hour BIT to $51.89 \%$ at 24 hours BIT. Slight fluctuations in BIT percentage recovery were observed between 24 and 120 hours. The change in oil recovery versus BIT curve is described to be sigmoidal. Comparatively,

The total oil recovered from primary recovery;

$$
\begin{aligned}
& =\frac{2.5}{12} \times 100=20.08 \% \quad \text { OOIP } \\
& =\frac{2.5}{12} \times 100=20.08 \quad \text { OOIP } \\
& =\frac{5.8}{12} \times 100=48.33
\end{aligned}
$$

Tertiary enhanced oil recovery using biosurfactant was

Table-4: Weight of samples

\begin{tabular}{|l|c|c|c|}
\hline \multicolumn{1}{|c|}{ parameter } & Trial 1 & Trial 2 & Trial 3 \\
\hline $\begin{array}{l}\text { Weight of empty } \\
\text { beaker }(\mathrm{g})\end{array}$ & 31.25 & 31.25 & 31.25 \\
\hline $\begin{array}{l}\text { Weight of beaker + } \\
\text { weight of dry sand (g) }\end{array}$ & 79.00 & 80.00 & 80.03 \\
\hline $\begin{array}{l}\text { Weight of beaker + } \\
\text { saturated sand (g) }\end{array}$ & 90.00 & 91.50 & 91.03 \\
\hline Weight of water(g) & 11.00 & 11.50 & 11.00 \\
\hline
\end{tabular}

Height of sand in core holder $=95.00 \mathrm{~mm}$

Diameter (internal) of core holder $=22.00 \mathrm{~mm}$

Table-5: Residual oil saturation, irreducible water saturation, residual oil saturation after biosurfactant action and percentage oil recovery at various BIT

\begin{tabular}{|c|c|c|c|c|c|c|}
\hline $\mathrm{BIT}(\mathrm{Hrs})$ & 0 & 24 & 48 & 72 & 96 & 120 \\
\hline $\mathrm{S}_{\mathrm{wi}} *$ & 0.091 & 0.109 & 0.087 & 0.093 & 0.099 & 0.103 \\
\hline $\mathrm{S}_{\text {or }}$ & 0.273 & 0.264 & 0.256 & 0.263 & 0.292 & 0.287 \\
\hline $\mathrm{S}_{\text {ore }}$ & 0.136 & 0.127 & 0.123 & 0.126 & 0.140 & 0.137 \\
\hline $\mathrm{R}^{* *}$ & 50.18 & 51.89 & 51.95 & 52.09 & 52.06 & 52.26 \\
\hline
\end{tabular}

*Irreducible water saturation, $\mathrm{S}_{\mathrm{wi}}$ is expressed

$$
S_{\text {wi }}=1-\frac{o_{i}}{v_{p}}
$$


where

$O_{\mathrm{i}}=$ oil injected $\left(\mathrm{cm}^{3}\right), W_{\mathrm{i}}=$ Water injected, $\left(\mathrm{cm}^{3}\right), N_{\mathrm{p}}=$ Oil produced (if any) $\left(\mathrm{cm}^{3}\right), \mathrm{Vp}=$ pore volume.

**Percentage oil recovery $(\mathrm{R})$ is given as;

$\mathrm{R}=\frac{\mathrm{S}_{\text {or }}-\mathrm{S}_{\text {ors }}}{\mathrm{S}_{\text {or }}} \times 100 \%$

where

$\mathrm{S}_{\mathrm{or}}=\quad$ Residual oil saturation after brine flooding (secondary recovery)

$\mathrm{S}_{\text {ore }}=$ Residual oil saturation after biosurfactant (tertiary recovery)

\section{DISCUSSION}

The process in enhanced oil recovery (EOR) techniques designed to recover oil, commonly described as residual oil after both primary and secondary recovery methods must have been employed is termed a called tertiary recovery technique. One of these tertiary methods of recovery involves microbial enhanced oil recovery (MEOR).However, the saturation of residual oil saturated sand pack (core) or reservoir at zero hour biosurfactant incubation time flow followed by "chases" brine, flooding produced about $50.18 \%$ of the in-place oil. A slight increase in recovery was obtained as the biosurfactant incubation time was increased to 24 hours through 120 hours. Maximum recovery of 52.26\% was obtained at $120 \mathrm{hrs}$ of biosurfactant incubation. This increase in percentage recovery was as a result of interfacial tension reduction by the biosurfactants. The only practical method of raising the capillary number for the reservoir to give improved recovery is by reducing the interfacial tension to very low value.

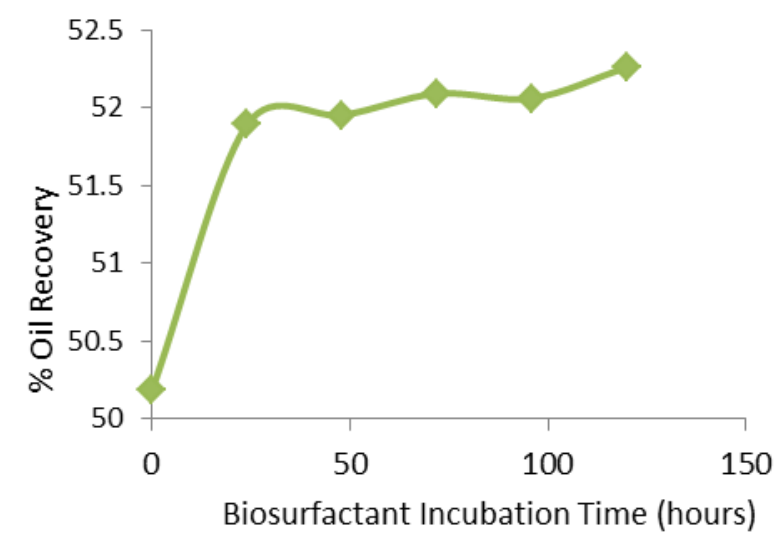

Fig -1: Showing the plot of oil recovery against BIT

\section{CONCLUSION}

The primary aim of this study to improve oil mobility and sweep efficiency using microorganisms (pseudomonas) was successfully achieved. Microbes grown on hydrocarbon produced interesting lipid \{Glycolipid and phospholipid\} surfactants in agreement with the reports of Singer and Finnerty [16]. Biosurfactants in the spent culture filtrates was observed to emulsify hydrocarbons, reduces the interfacial tension, thereby causing facilitating mobilization of the test crude. These findings are in conformity with that of Okorie [8]. Although biosurfactants are not currently considered as chemical enhanced oil recovery agents in the oil industry, potential applications have been indicated for these bioproducts in chemical flooding as revealed in the study of Finnerty et al [9]. This work has demonstrated that biosurfactant produced by pseudomonas species grown on hydrocarbon (kerosene) was able to mobilize residual oil and can be applicable on the field scale. It is therefore recommended to test and confirm the lab-obtained result since a lab-scale cannot accurately commensurate for field application.

\section{REFERENCES}

[1] Davis, J.B.: "Petroleum Microbiology".Elsevier Scientific Publishing C. Amsterdam, The Netherlands, pp 120-125, 1978.

[2] Clark, J. B, Munnecks, D. M. and Jenneman G. E.: “Insitu Microbial Enhanced Oil Production”. Dev. Ind Microbial pp 695-701, 1981.

[3] Westlake, D. W.S,:n Heavy Crude oil and Oil Shale Tertiary Recovery Of Petroleum From Oil Bearing Formations.” Petroleum Microbiology, Macmillian, New york, pp 537-552, 1884. 
[4] Jack, T. R, Blasio, E. D, Thomason B. G and Ward V.: “ Bacterial Systems For Selective Plugging in Secondary Oil production." International bio resources , 1985.

[5] Jang, L. K., Sharma, M. M., Findely, J. F., Chang, P.W., and Ten, T.F.:”An Investigation of Transport Of Bacteria Through The Porous Media." Prod Int Cont, Microbial Enhanced Oil Recovery, Alfton, Oklahoma DOE cont-820514D, pp 60-70. 1982

[6] Bryant, R.S and Douglas J.: “ Survival of MEOR Systems In Porous Media”, Department of Energy, Report No 105, 1986.

[7] Okpokwasili, G.C, Somerville, C.C, Sullivan, M., Grimes, D. J, and Colwell, R.R.:” Plamid Mediated Degradation of Hydrocarbon in Estrudine Bacteria pp 117-129, 1986.

[8] Okorie, B.B: "Suitability of Downhole Bacterial Isolates in Tertiary Oil Recovery Technology".1991

[9] Finnerty, W. R.: "application of Microbial Process to viscosity Reduction of Heavy Oil recovery". DOE/bc/10507 pp 1923 - 1987.

[10] Ukpe J. J.: "Effects of workover/ completion Fluids and Additives in relation to permeability characteristics." Petroleum Department, University of Port Harcourt, Nigeria, 1992.

[11] Mills, A. L. Brevil, C. and Colwell, R. R.:Enumeration of Petroleum Degrading Marine and Estuarine Microorganisms by the most probable number method.” J. Microbial pp 552- 557, 1978.

[12] Gerhart, F. Murray, R. G. E, Nester E. W., Wood, W. A.: " Manual of Methods for General Bacteriology". American Society of Microbiology, Washington D.C

[13] Jones, J. G.: "Long term Effects of Kerosine Polution on The Microflora of a Moorland Soil." J. Appl. Bacteria. Pp 123-128.

[14] Rosenmberg, M and Rosenberg , E,: Bacterial Adherence at the Hydrocarbon - Water interface." Volume 2, pp 155-162.

[15] Gutnick, E. L and Rosenberg.E.: “Oil Tankers Polution; A Microbial Approach.” Pp 319 - 396, 1977.

[16] Singer, J. T., Finnerty, W. R.: "Generation of Hydrocarbon Utilizing Microoragnisms in Petroleum Microbiology." pp 551986. 